From the Department of Oncology, Georgetown University Medical Center, and Cancer Control Program, Lombard Cancer Center, Washington, DC; Department of Family Medicine, Albert Einstein School of Medicine, Bronx; City University of New York, New York Health Policy Research Center at the Robert J. Milano Graduate School of Management and Urban Policy at the New School for Social Research, New York, NY; and the Department of Health Studies and University of Chicago Cancer Research Center, University of Chicago, Chicago, IL.

Submitted May 1, 2003; accepted March 24, 2004.

Supported by grants K05 CA96940 (J.S.M.) and RO1 CA72908 (J.S.M. K.R.Y., C.B.S., P.M., and M.F.) and cooperative agreement No. UO1CA88293A from the National Cancer Institute (J.S.M., K.R.Y.,W.L., C.B.S. J.C., Y.C., and J.D.), Bethesda, MD.

Authors' disclosures of potential conflicts of interest are found at the end of this article.

Address reprint requests to Jeanne Mandelblatt, MD, MPH, Lombardi Cancer Center, 2233 Wisconsin Ave, Suite 317, Washington, DC 20007; e-mail:

mandelbj@georgetown.edu.

(c) 2004 by American Society of Clinical Oncology

0732-183X/04/2213-2554/\$20.00

DOI: 10.1200/JCO.2004.05.009

\title{
Benefits and Costs of Interventions to Improve Breast Cancer Outcomes in African American Women
}

Jeanne S. Mandelblatt, Clyde B. Schechter, K. Robin Yabroff, William Lawrence, James Dignam, Peter Muennig, Yoko Chavez, Jennifer Cullen, and Marianne Fahs

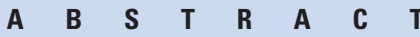

\section{Purpose}

Historically, African American women have experienced higher breast cancer mortality than white women, despite lower incidence. Our objective was to evaluate whether costs of increasing rates of screening or application of intensive treatment will be off-set by survival benefits for African American women.

\section{Methods}

We use a stochastic simulation model of the natural history of breast cancer to evaluate the incremental societal costs and benefits of status quo versus targeted biennial screening or treatment improvements among African Americans 40 years of age and older. Main outcome measures were number of mammograms, stage, all-cause mortality, and discounted costs per life year saved (LYS).

\section{Results}

At the current screening rate of $76 \%$, there is little incremental benefit associated with further increasing screening, and the costs are high: $\$ 124,053$ and $\$ 124,217$ per LYS for lay health worker and patient reminder interventions, respectively, compared with the status quo. Using reminders would cost $\$ 51,537$ per LYS if targeted to virtually unscreened women or $\$ 78,130$ per LYS if targeted to women with a two-fold increase in baseline risk. If all patients received the most intensive treatment recommended, costs increase but deaths decrease, for a cost of $\$ 52,678$ per LYS. Investments of up to $\$ 6,000$ per breast cancer patient could be used to enhance treatment and still yield cost-effectiveness ratios of less than $\$ 75,000$ per LYS.

\section{Conclusion}

Except in pockets of unscreened or high-risk women, further investments in interventions to increase screening are unlikely to be an efficient use of resources. Ensuring that African American women receive intensive treatment seems to be the most cost-effective approach to decreasing the disproportionate mortality experienced by this population.

J Clin Oncol 22:2554-2566. (c) 2004 by American Society of Clinical Oncology

\section{INTRODUCTION}

Breast cancer is second only to lung cancer as the leading cause of potentially avoidable cancer mortality among women. ${ }^{1,2}$ In the last two decades, the mortality rate from breast cancer has decreased by approximately $7 \%$ in younger white women. ${ }^{1}$ However, African American women have yet to realize similar mortality reductions, and older African American women have experienced an increase in mortality, despite a lower incidence of disease than their white counterparts. $^{1,3}$ A portion of the excess mortality seen in African American women could be caused by low rates of screening, failure to receive timely and complete diagnostic follow-up, or receiving suboptimal treatment. For instance, historically, African American women had significantly lower rates of mammography screening ${ }^{4-6}$ and later-stage diagnosis ${ }^{7-12}$ than did white women. Although disparities in screening rates have significantly diminished in recent years, ${ }^{13}$ some, such as poor, minority, and older women, still remain at risk for having their cancers detected at later stages. ${ }^{7}$ Once African American women are screened, if 
they have cancer, treatment is often suboptimal. ${ }^{3,14-16}$ Thus, there are important points in the process of breast cancer control where interventions could potentially reduce the disproportionate morbidity and mortality observed in African American women.

Prior cost-effectiveness analyses of breast cancer screening have demonstrated that reductions in mortality can be achieved at a reasonable cost per life year saved in general $^{17-21}$ as well as in selected groups of older ${ }^{22-25}$ and/or older African American women. ${ }^{25}$ However, there are no data regarding whether additional expenditures to enhance the cancer control process for African American women would result in improved overall survival at reasonable societal expenditures.

In this study, we use a model simulating the natural history of breast cancer to test the hypothesis that the added costs of targeted programs to increase screening or enhance receipt of intensive systemic treatment will be off-set by the downstream benefits of increased survival among African American women who develop breast cancer.

\section{METHODS}

We used an event-driven, continuous-time Monte Carlo simulation model to evaluate the costs, harms, and benefits of adding new cancer control interventions to current United States patterns of care for African American women. We compared targeted clinical screening interventions (patient reminders or lay health worker) versus status quo biennial screening or receiving optimal treatment (consistent with current recommendations) versus current patterns of care. We calculated incremental cost-effectiveness ratios, where the additional costs of a strategy, divided by the added savings in life years, are compared with the next least expensive effective strategy. ${ }^{26} \mathrm{We}$ also calculated intermediate outcomes, including number of abnormal mammograms, number of falsepositives, number of cancers diagnosed, and stage distribution associated with each strategy. All costs and effects are discounted at $3 \% .{ }^{26}$ All scenarios were examined by generating 1.25 million simulated patients, a sample size chosen to ensure that the SE of the estimated population life expectancy would be less than 2 days. We used a matched simulation approach to maximize computer resource efficiency and maximize the precision of our effect estimates. ${ }^{27}$ Briefly, in the analyses of screening interventions as an example, each simulated woman is simulated twice: once with screening and the other time without. The random numbers used for all variables simulated for the woman are identical in the two simulations (matched), except for the fact of screening and the events after screening. The comparison between intervention scenarios was then made by varying the proportion of simulated women who are screened versus unscreened in the given scenario.

\section{Disease Natural History Model}

We developed Monte Carlo simulations ${ }^{28}$ to portray the dynamic processes of breast cancer incidence, detection, progression, and treatment (Fig 1). The model begins with a hypothetical cohort of 40-year-old African American women and randomly assigns dates of death, symptomatic breast cancer incidence, and date of first and subsequent biennial screening mammograms. For instance, women who are destined to get breast cancer are assigned a date at which symptomatic illness will present. The stage of symptomatic presentation is selected randomly from age-specific distributions in unscreened women. If women are screened and the tumor is detected before this time (a true-positive screen), a new stage is calculated using Bayes' theorem with a prior distribution taken from screened breast cancer incidence rates and a conditional distribution calculated from the rates of transition through the stages (ductal carcinoma-in-situ [DCIS], local, regional, and distant) and the simulated lead time. Women who are screened but do not have their tumor detected (false-negative) return to routine screening; their tumor may be detected on subsequent screening rounds or they may present with symptomatic disease. When women develop breast cancer, they are also randomly assigned an estrogen receptor (ER) status based on their age and race (African American or not). Treatment is randomly selected based on current patterns of care, given age, African American race, stage at presentation, and ER status. Recurrence and survival probabilities are assigned based on this selection.

For women who do not develop cancer, the probability of a false-positive mammogram is based on the general age-specific specificity of mammogram and the number of mammograms received between age 40 years and the date of death. Finally, interventions designed to improve screening use and rates of receipt of intensive treatment modify events in the model (eg, increase probability of screen detection, increase survival through use of chemotherapy to treat ER-negative disease). We chose a biennial screening interval because this is the standard tested in randomized trials and the interval used in most prior costeffectiveness analyses of breast screening.

\section{Model Assumptions}

There are several underlying assumptions in our model (Table 1). The key assumption is that the differences in distribution of ER status by race represent a proxy for general race-specific differences in tumor markers. Although biologic factors seem to only account for a small proportion of the variance in survival between African American and white women, ${ }^{29,30}$ African American women are significantly more likely to have ER-negative tumors than white women, ${ }^{31}$ and stage for stage, women with ER-negative tumors have shorter disease-free and overall survival than women with ER-positive tumors. ${ }^{30,32-34}$ Although other markers of biologic variability, such as tumor differentiation, ${ }^{35} \mathrm{~S}$-phase fractions, ${ }^{30}$ and new genetic biomarkers (eg, erb-b-2), ${ }^{35,36}$ also affect survival and may vary by race, there are presently insufficient race-specific treatment and survival data by these markers to include in our model.

Second, at this time there are insufficient good-quality ERstratified survival data for DCIS, so we assume that all women diagnosed with carcinoma-in-situ will have overall age-specific DCIS survival. We also make the simplifying assumption that lobular carcinoma-in-situ and DCIS have the same natural history and survival.

Next, although there are good-quality data for the short-term effects of the screening interventions we evaluate, there are little data available to describe their long-term effects. Although there is some evidence that effectiveness declines over time to baseline, ${ }^{37}$ we model the interventions as having an enduring effect on the relative risk of remaining unscreened (favors enhanced screening). Fourth, because the age-, ER-, and treatment-stratified survival we used were based on up to 15 years of observation, we made several simplifying assumptions about average survival beyond this period. We assumed that women either diagnosed with DCIS 


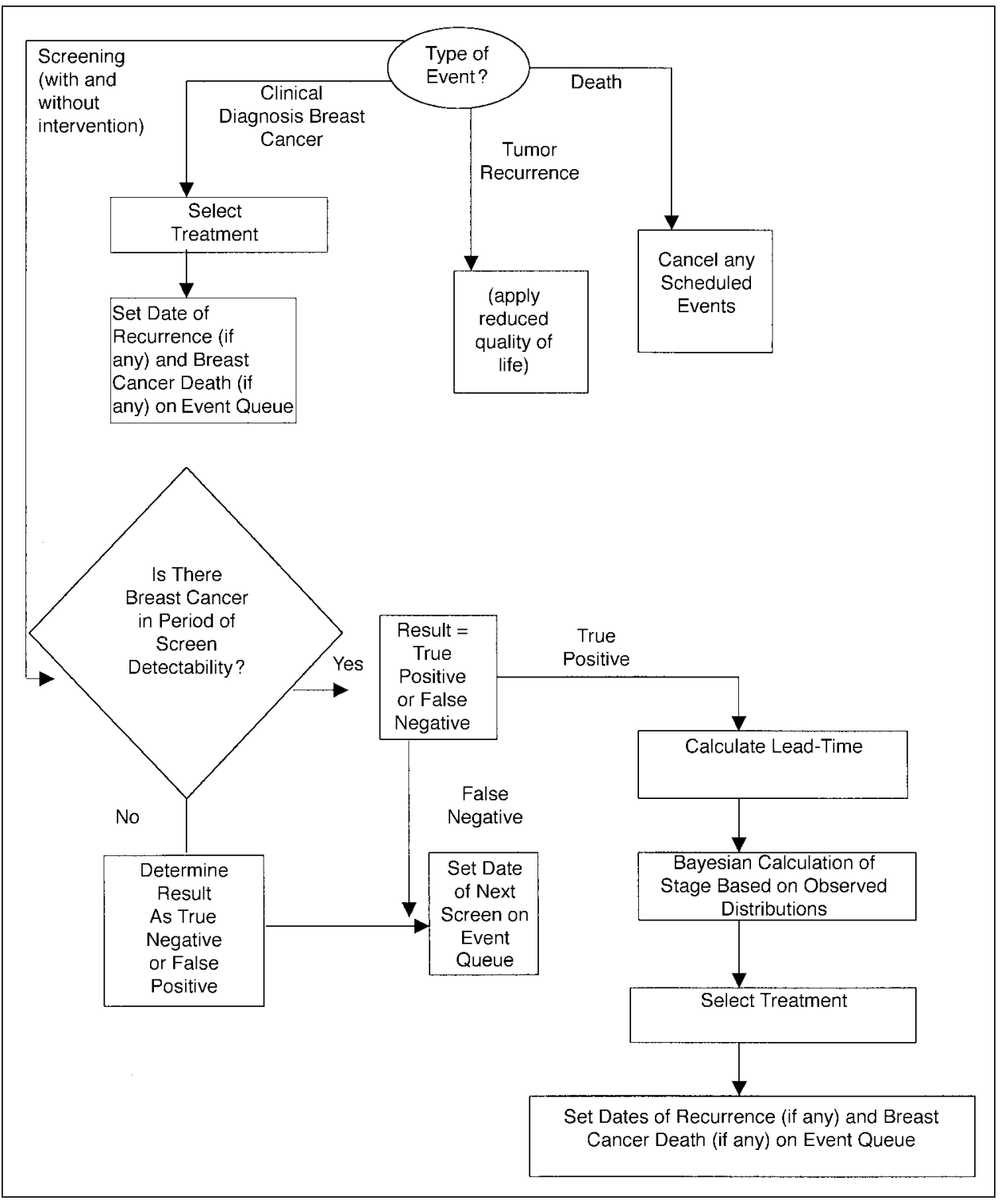

Fig 1. Model structure for evaluating the benefits and costs of breast cancer-control intervention to improve outcomes in African Americans. Flow of events processed in the simulation of the natural history of breast cancer is shown. Some events incur costs or quality-of-life reductions. At the end of the simulation, events are tallied, and costs and quality adjustments are applied.

destined to progress to local stage-invasive disease or those diagnosed with local stage who survived for 15 years without recurrence would have similar survival after that time as their age- and race-matched non-breast cancer cohort (eg, are cured). Survival for women with DCIS and local disease who have recurrent disease at 15 years, or for women with regional disease surviving 15 years, was estimated using stage-specific declining exponential approximation of life expectancy. ${ }^{38} \mathrm{We}$ also assume that survival is the same for women with screen-detected and clinically detected cancers. This assumption is likely to underestimate the effectiveness of mammography.

Finally, in our model, the effectiveness of mammography is represented purely by the resulting stage shift. We use the stage distributions of tumors observed in a period before mammography (1975 to 1979) and in the current period (1995 to 2001) when use was high to represent the stage distributions of clinically detected and screen-detected lesions, respectively.

\section{Model Parameters}

To estimate the probability of all costs and events in the model, we reviewed the literature for population-based studies applicable to African Americans. If race-specific data were not available, we used data from the general population. Parameters are listed in Tables 2 and 3.

\section{Disease Natural History}

Breast cancer incidence rates for African American women were estimated from Surveillance, Epidemiology, and End Results (SEER) data. ${ }^{1}$ Stage distributions for screened and unscreened women were taken from two different sources. Data from SEER from 1975 to 1979 were used to approximate the distribution of events in the absence of screening. ${ }^{1}$ Data from the Breast Cancer Surveillance Consortium ${ }^{39}$ from 1995 to 2001 were used to represent the stage distribution for screen-detected African American women (Breast Cancer Surveillance Consortium, W. Barlow, per- 


\begin{tabular}{|l|}
\hline Table 1. Model Assumptions \\
\hline Disease biology \\
ER status is a proxy for race differences in biology of invasive \\
cancer \\
Lobular and ductal in-situ cancers have the same survival \\
Survival after 15 years \\
DCIS and local = general population \\
Regional or recurrent disease = DEALE \\
Screen-detected and clinically detected cancers have the same \\
survival \\
Screening \\
Intervention effects persist over the long term \\
Abbreviations: ER, estrogen receptor; DCIS, ductal carcinoma-in-situ; \\
DEALE, declining exponential approximation of life expectancy.
\end{tabular}

sonal communication, June 2002). Screen-detected cancer was defined as a cancer diagnosed within 3 months of a positive screening mammogram performed in the absence of symptoms; screening intervals reflected average population use. Because women who were reported as having stage unknown in SEER ${ }^{1}$ in both periods had survival rates between those of women with regional and distant disease. Therefore, among the $10 \%$ of women with missing stage for each period, we reassigned $50 \%$ as regional and $50 \%$ as distant.

Time to stage progression (eg, from DCIS to invasive cancer, from local to regional disease, or from no active disease to recurrence) was estimated based on data from randomized clinical trials of breast cancer screening and simulating stage distributions in the screened and unscreened settings. ${ }^{40-44}$ Average dwell times were assumed to have an exponential distribution. ${ }^{43,44}$

\section{Test Characteristics}

We used age-specific test characteristics ${ }^{45}$ for all races of women, because the health-insurance plan trial demonstrated similar effects of mammography on mortality for African American and white women. ${ }^{40}$ We use different values for the sensitivity and specificity of the first versus subsequent mammogram, because the first screen detects more prevalent than incident disease. Prevalent tumors are, on average, larger than incident tumors, and potentially easier to detect than new tumors. ${ }^{45}$

\section{Rates of Mammography Use}

Current rates of recent mammography use are, on average, quite high $(76 \%) .{ }^{4}$ Because average rates may mask pockets of underscreening, we tested the cost-effectiveness of enhanced screening interventions across a range of baseline screening rates in sensitivity analyses.

\section{Interventions to Improve Mammography Use}

We evaluated the effects (and costs, discussed further herein) of patient reminder letters ${ }^{46-48}$ and outreach by lay health workers $^{49-53}$ to increase use of initial and subsequent screening. We also considered but did not include other interventions, including church-based workers, theory-based educational counseling telephone calls, scheduling of mammography the same day as the medical referral visit, and physician reminders or audit with feedback to prompt physicians to order screening. ${ }^{79,80}$ These latter interventions were not included because they were of similar or lesser effectiveness and/or were more costly than patient reminders and lay workers.
To estimate the effect of patient reminders and lay health workers, we combined data from studies in random-effects metaanalysis models to calculate the relative risk of remaining unscreened after the one-time application of the intervention.

\section{Diagnostic Evaluation}

We assumed that women with an abnormal mammogram undergo diagnostic evaluation; women who have breast cancer also have a staging evaluation.

\section{Treatment}

Current patterns of age-, race-, and stage-specific local surgical therapy were estimated from SEER public use files. ${ }^{1}$ We assumed that initial decisions about use of mastectomy, breast conservation, and radiation are independent of ER status. Age- and race-specific patterns of adjuvant treatment were estimated from published data. ${ }^{54}$ These latter data are not available by ER status.

\section{Improving Treatment Patterns}

Rates of use of adjuvant therapies are below those advocated by professional groups. ${ }^{55,56}$ We assessed the effectiveness of providing all women with the most intensive indicated adjuvant therapy, defined as all women with ER-negative invasive tumors receiving multiagent chemotherapy and all women with ERpositive invasive tumors receiving both multiagent chemotherapy and tamoxifen. Because we are not aware of any interventions to increase use of chemotherapy, we calculated a cost threshold.

\section{Life Expectancy}

The probability of dying within each 1-year age interval beginning at age 40 years was abstracted from life tables for African American women compiled by the National Center for Health Statistics. ${ }^{81}$ For women with breast cancer, we used pooled data from thirteen National Surgical Adjuvant Breast and Bowel Project treatment trials evaluating surgery, radiotherapy, hormonal therapy, and chemotherapy treatments among approximately 20,000 women to estimate relapse-free and overall survival up to 15 years by stage, treatment, age ( $<40$ years; 40 to 49 years; 50 to 59 years; $60+$ years $)$, and ER status. ${ }^{57-69}$

\section{Costs}

We included medical care (consumable supplies, personnel, laboratory, and procedure costs) and nonmedical care (patient time costs) direct costs (Table 3). All costs are converted to year 2000 United States dollars using the medical care component of the consumer price index for the year of data collection. ${ }^{82}$ The cost of routine screening mammography was based on an extended office visit to discuss mammography plus the costs of a mammogram. ${ }^{70,71}$ Costs of an evaluation of a false-positive abnormal mammogram were estimated to be $\$ 93.35 .^{72}$ The costs of cancer diagnosis, treatment, continuing, and terminal care were estimated from linked SEER-Medicare reimbursement data from 1990 to 1999 using the method described by Warren et $\mathrm{al}^{73}$ and Brown et al. ${ }^{83}$ These phase-specific data do not specify the costs for specific therapies; rather, they provide an average of the costs of all regimens actually consumed by women in the period of observation. We assume that Medicare reimbursements, which are based on the Medicare Resource-Based Relative Value Scale, closely approximate societal costs. ${ }^{84}$ Because Medicare does not cover the costs of tamoxifen, we added the wholesale costs of tamoxifen for women receiving this treatment. ${ }^{77}$ The costs of optimal treatment were based on Medicare costs plus the added costs of tamoxifen and chemotherapy; chemotherapy costs were based on wholesale costs. ${ }^{77}$ Because some chemotherapy 
Table 2. Natural History of Disease Parameters in African American Women

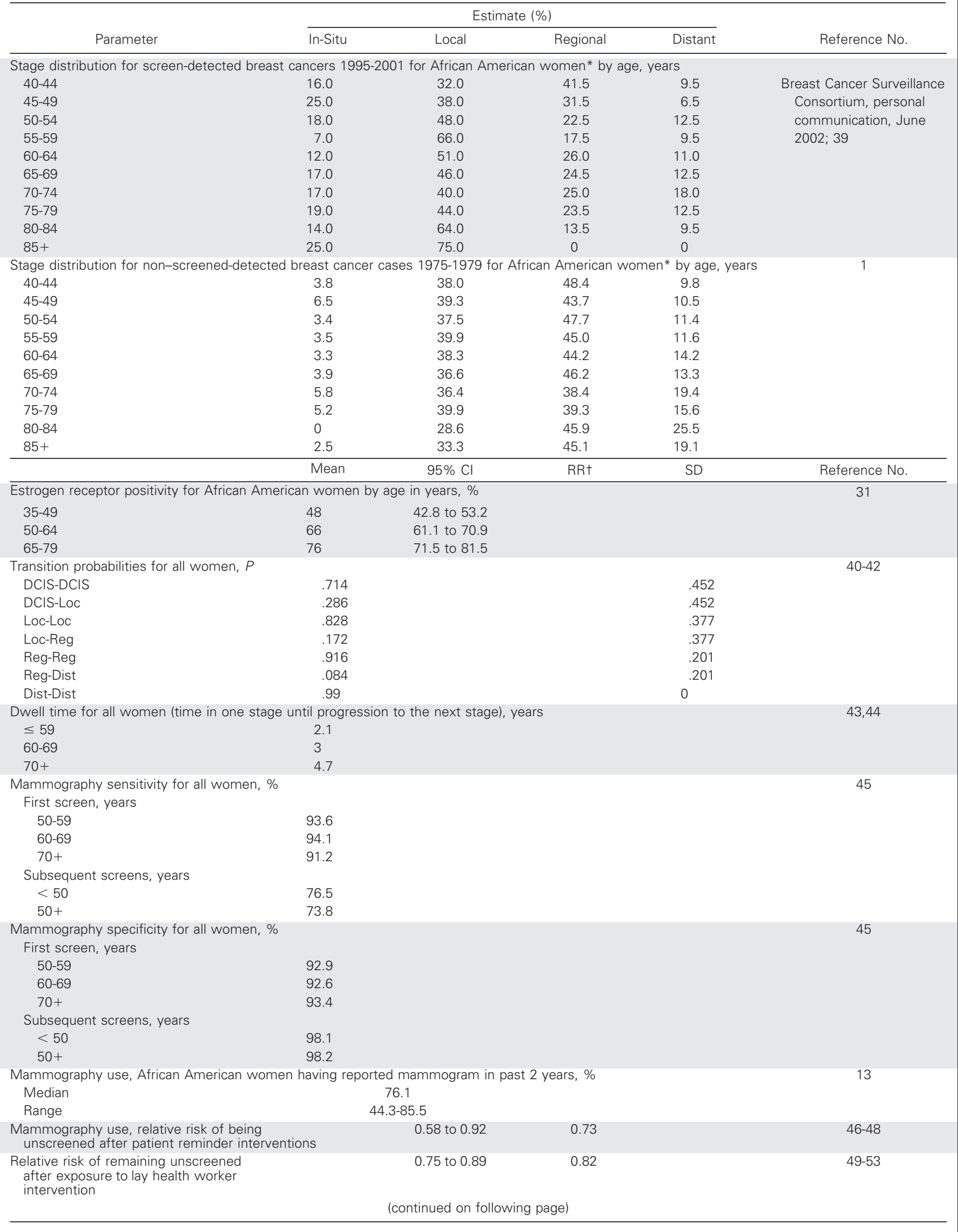


Table 2. Natural History of Disease Parameters in African American Women (continued)

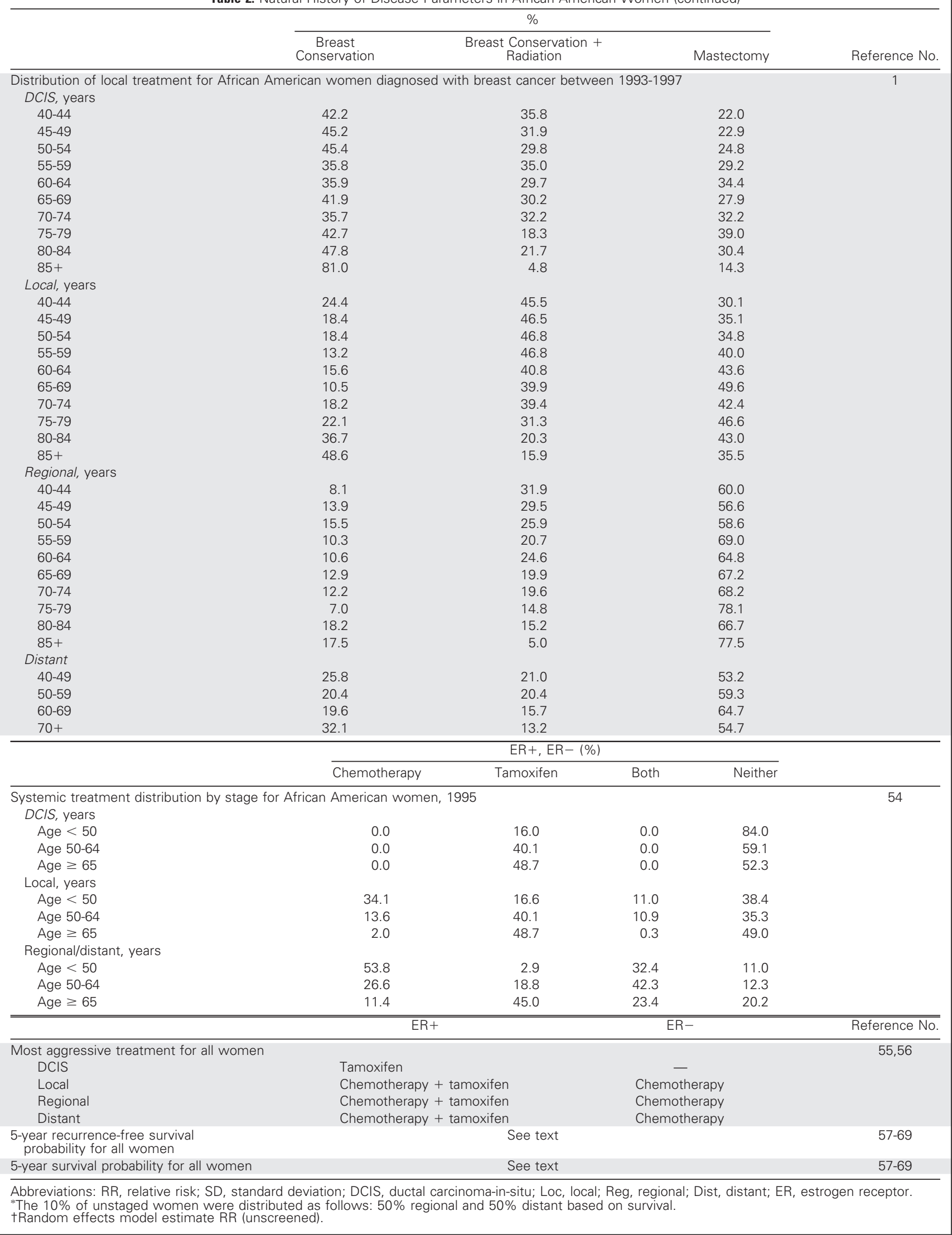


Table 3. Costs of Breast Cancer Care (year 2000 costs)

\begin{tabular}{|c|c|c|c|c|c|c|c|c|c|}
\hline \multirow[b]{3}{*}{ Cost Parameter } & \multirow[b]{3}{*}{ Estimate (\$) } & \multicolumn{7}{|c|}{ Treatment (\$) } & \multirow[b]{3}{*}{ Reference No. } \\
\hline & & \multicolumn{2}{|c|}{$\begin{array}{c}\text { Breast- } \\
\text { Conserving } \\
\text { Surgery }\end{array}$} & \multicolumn{2}{|c|}{$\begin{array}{c}\text { Breast } \\
\text { Conservation } \\
+ \text { Radiation }\end{array}$} & \multicolumn{2}{|c|}{ Mastectomy } & \multirow[b]{2}{*}{ Chemotherapy } & \\
\hline & & Mean & $\mathrm{SD}$ & Mean & $\mathrm{SD}$ & Mean & $\mathrm{SD}$ & & \\
\hline $\begin{array}{l}\text { Mammography interpretation } \\
\text { for all women }\end{array}$ & 52.51 & & & & & & & & 70,71 \\
\hline Mammography visit & 30.00 & & & & & & & & 70,71 \\
\hline $\begin{array}{l}\text { Total cost of evaluating abnormal } \\
\text { mammogram for all women }\end{array}$ & 95.35 & & & & & & & & 71,72 \\
\hline \multicolumn{8}{|c|}{$\begin{array}{l}\text { Average monthly treatment costs for African American women by phase and stage } \\
\text { Initial phase } \dagger\end{array}$} & & 72,73 \\
\hline DCIS & & 448 & 89 & 2,073 & 186 & 1,646 & 177 & & \\
\hline Local & & 1,355 & 107 & 2,261 & 166 & 1,874 & 201 & & \\
\hline Regional & & 2,217 & 390 & 2,597 & 179 & 2,435 & 112 & & \\
\hline Distant & & 2,434 & 616 & 2,852 & 454 & 2,623 & 296 & & \\
\hline \multicolumn{10}{|l|}{ Continuing phase } \\
\hline DCIS & & 148 & 49 & 198 & 58 & 152 & 39 & & \\
\hline Local & & 241 & 43 & 156 & 29 & 210 & 22 & & \\
\hline Regional & & 289 & 116 & 166 & 47 & 212 & 28 & & \\
\hline Distant & & 394 & 201 & 573 & 208 & 196 & 117 & & \\
\hline \multicolumn{10}{|l|}{ Terminal phase§ } \\
\hline DCIS & & 2,168 & 455 & 1,266 & 890 & 2,505 & 663 & & \\
\hline Local & & 3,283 & 400 & 2,583 & 365 & 3,318 & 833 & & \\
\hline Regional & & 2,469 & 472 & 3,204 & 338 & 2,731 & 271 & & \\
\hline Distant & & 3,146 & 693 & 3,173 & 425 & 2,785 & 519 & & \\
\hline \multicolumn{6}{|c|}{$\begin{array}{l}\text { Monthly patient time costs (travel, treatment) } \\
\text { Initial phase }\end{array}$} & & & & $74-76$ \\
\hline All stages & & \multicolumn{2}{|c|}{26} & \multicolumn{2}{|c|}{91} & \multicolumn{2}{|c|}{61} & 39 & \\
\hline \multicolumn{10}{|l|}{ Continuing phase } \\
\hline DCIS/local & & \multicolumn{2}{|c|}{ 5.08/year } & \multicolumn{2}{|c|}{ 5.08/year } & \multicolumn{2}{|c|}{ 5.08/year } & 5.08/year & \\
\hline Regional/distant & & \multicolumn{2}{|c|}{ 6.33/year } & \multicolumn{2}{|c|}{ 6.33/year } & \multicolumn{2}{|c|}{ 6.33/year } & $6.33 /$ year & \\
\hline \multicolumn{10}{|l|}{ Terminal phase } \\
\hline All stages & & \multicolumn{2}{|c|}{10} & \multicolumn{2}{|c|}{10} & \multicolumn{2}{|c|}{10} & 10 & \\
\hline $\begin{array}{l}\text { Cost of tamoxifen over 5-year } \\
\text { period }\end{array}$ & 6,352 & & & & & & & & 77 \\
\hline Cost of adjuvant chemotherapy & 4,725 & & & & & & & & 77 \\
\hline for initial treatment & & & & & & & & & \\
\hline $\begin{array}{l}\text { Interventions to enhance } \\
\text { screening for all women\| }\end{array}$ & (per patient) & & & & & & & & $74,75,78$ \\
\hline Reminder letter & 56 & & & & & & & & \\
\hline Lay health worker & 63 & & & & & & & & \\
\hline
\end{tabular}

Abbreviation: DCIS, ductal carcinoma-in-situ.

* Year 2000 dollars.

†The initial phase of care includes all costs incurred by breast cancer patients for the 12-month period after the date of diagnosis (eg, initial evaluation, hospitalizations, and surgery, and any adjuvant chemotherapy, medical visits, laboratory procedures). ${ }^{73}$

¥The continuing care phase includes all costs after the initial phase up to the 12 months period to death (eg, medical visits, hospitalizations, mammograms, laboratory procedures, etc). ${ }^{73}$

$\S$ Terminal care costs refer to all costs in the last 12 months of life (eg, hospitalizations, chemotherapy, laboratory procedures, and medical visits). ${ }^{73}$ ||lnterventions were micro costed.

costs are already included in the Medicare costs, we overestimated costs, which biases against interventions to enhance therapy.

Costs associated with the screening interventions were calculated using micro-costing methods. Nonmedical costs included patient time spent receiving screening, diagnostic evaluation, and treatment, and travel and waiting time for receiving care. Average travel and waiting times and time spent receiving services were estimated from prior research and clinical estimates. ${ }^{74-76}$ Costs were obtained by multiplying these times by median United States wage rates for African American women. ${ }^{82}$ The costs of lost pro- ductivity as a result of breast cancer morbidity and mortality would be accounted for by decrements in utilities used to qualityadjust years of life saved (see next section).

\section{Sensitivity Analyses}

We varied individual parameters and combinations of parameters over different ranges to examine the robustness of the model results under a variety of conditions. We used life years saved as our base model because utilities did not affect conclusions. Quality-adjusted life years are examined in sensi- 
tivity analyses (1.0, healthy, no cancer; 0.85 , local; 0.7 , regional; 0.5 , distant).

\section{Model Validation and Statistical Testing}

Programming accuracy was verified using input designed to test the model under hypothetical conditions in which the results should be obvious. Our scientific advisors reviewed model face and clinical validity.

\section{Role of Funding Source}

The funding agencies had no role in data analysis, interpretation of results, or decisions to publish the results.

\section{RESULTS}

\section{Screening}

African American women have a 7.2\% cumulative risk of developing breast cancer from age 40 years to death in our simulation. At status quo baseline screening rates of $76 \%$, with a program of biennial screening beginning at age 40 years, each woman will undergo an average of 10 mammograms in her lifetime and has a 54\% cumulative risk of having a false-positive screening result in this period (Table 4). Compared with no screening, screening saves 11 days of life per capita (undiscounted).

Using patient reminders or lay workers increases the average number of mammograms from the status quo by less than one over a lifetime and increases the risk of a false-positive screen by $6.5 \%$. At current screening levels, enhanced screening efforts are associated with only a slight increase in population life expectancy after age 40 years ( $<1$ day per woman, undiscounted); there is only a marginal difference between the two approaches. Among women destined to develop breast cancer, increasing screening saves an additional 11 days of life compared with the current status quo.

The incremental cost-effectiveness ratios associated with increased screening resulting from patient reminders and lay navigation are shown in Table 4 . Comparing each approach to the status quo, both result in cost-effectiveness ratios of greater than $\$ 100,000$ per life year saved. These high costs reflect increased use of mammography and earlier expenditures on treatment without appreciable benefits in life extension.

\section{Treatment}

Compared with current patterns of care, if all women were to receive the most intensive systemic therapy, an average of 0.053 years or 19.3 additional days would be saved, spread out over the entire population (undiscounted). These savings are attributable to the additional savings of 266 days of life among the breast cancer patients. If all women received the most intensive treatment recommended in consensus guidelines compared with status quo patterns, it would cost $\$ 52,678$ per life year saved (Table 4). Investments in interventions to enhance treatment adherence to this level of up to $\$ 6,000$ per breast cancer patient would still yield cost-effectiveness ratios of less than $\$ 75,000$ per year of life saved.

\section{Sensitivity Analysis}

If we assume maximal screening intervention effectiveness of patient reminders and apply the intervention in populations of women with the lower bound of current screening rates $(44 \%)$, the cost per life year saved remains high: \$98,447 compared with the status quo. However, investments in enhanced screening (eg, reminders) become cost-effective in areas with pockets of unscreened or very underscreened women (eg, \$51,537 compared with no screening). If screening is targeted to women with a twofold baseline increase in risk of developing breast cancer (eg, a first-degree relative with breast cancer), then enhanced screening using patient reminders has greater benefits than in the general population, and results in a cost-effectiveness ratio of $\$ 78,129$ per life year saved compared with the status quo situation.

\begin{tabular}{|c|c|c|c|c|c|c|c|}
\hline Strategy & $\begin{array}{c}\text { No. of } \\
\text { Mammograms }\end{array}$ & $\begin{array}{l}\text { No. of False } \\
\text { Positives }\end{array}$ & $\begin{array}{c}\text { Costs } \\
\text { (3\% discounted, } \$ \text { ) }\end{array}$ & $\begin{array}{l}\text { Incremental } \\
\text { Costs }(\$)\end{array}$ & $\begin{array}{c}\text { Life Expectancy } \\
\text { (3\% discounted, years) }\end{array}$ & $\begin{array}{l}\text { Incremental Life } \\
\text { Expectancy (years) }\end{array}$ & $\begin{array}{l}\text { Incremental Cost } \\
\text { Effectiveness }(\$)\end{array}$ \\
\hline No screening & - & - & $3,511.93$ & N/A & 21.299179 & N/A & N/A \\
\hline $\begin{array}{l}\text { Status quo screening } \\
\text { and treatment* }\end{array}$ & 9.97 & 0.66 & $4,138.93$ & 627.00 & 21.30649 & 0.007312 & $85,755 / L Y$ \\
\hline $\begin{array}{l}\text { Lay health worker } \\
\quad v \text { status quo }\end{array}$ & 10.53 & 0.70 & $4,238.18$ & 99.24 & 21.307290 & 0.000800 & 124,053/LY \\
\hline $\begin{array}{l}\text { Patient reminder } v \\
\text { status quo }\end{array}$ & 10.82 & 0.71 & $4,247.00$ & 108.07 & 21.30736 & 0.000870 & 124,217/LY \\
\hline $\begin{array}{l}\text { Enhanced treatment } \\
\quad v \text { status quot }\end{array}$ & 9.97 & 0.66 & $5,143.50$ & 1004.57 & 21.32556 & 0.019070 & $52,678 / \mathrm{LY}$ \\
\hline \multicolumn{8}{|c|}{$\begin{array}{l}\text { Abbreviations: N/A, not applicable; LY, life years. } \\
\text { *Status quo is compared with no screening. Status quo treatment refers to patterns of care reported to Surveillance, Epidemiology and End Results. }{ }^{1,54} \\
\text { †All women receive intensive therapy following consensus guidelines (surgery [and radiation after lumpectomy] plus adjuvant therapy, where all women with } \\
\text { local and regional disease who are estrogen receptor-negative receive chemotherapy; women who are estrogen receptor-positive receive tamoxifen and } \\
\text { chemotherapy). }{ }^{55,56}\end{array}$} \\
\hline
\end{tabular}


Adjustment for a range of utility values does not change the conclusion that enhanced screening is not cost-effective at current screening levels (eg, using patient reminders $v$ status quo screening is also very expensive when utilities are considered, costing $\$ 200,000$ per quality-adjusted life years). Delays in the timing of diagnostic evaluation of an abnormal screening test decrease the cost-effectiveness ratios for screening minimally, because delay would have to lead to stage progression from one stage to the next to have a significant impact on life expectancy (data not shown).

\section{DISCUSSION}

This is the first analysis that we are aware of that examines the cost effectiveness of breast cancer screening in African American women and examines the costs and benefits of enhancing screening or treatment. Overall, our results suggest that maximal improvements in breast cancer outcomes could be achieved by concentrating resources on delivery of the most intensive treatment regimens to all African American patients with breast cancer. Additional investments in screening should be reserved for situations in which there are pockets of unscreened women or for ensuring that all high-risk women are screened.

Meta-analyses of breast cancer polydrug chemotherapy and tamoxifen clinical trials have demonstrated statistically significant reductions in overall mortality in general populations around the world. ${ }^{85,86}$ On the basis of these results, current standards of care for local and regional breast cancer include recommendations for systemic treatment. ${ }^{55,56}$ Currently, there is no evidence to suggest that chemotherapy pharmacokinetics, which may differ by race, influence treatment effectiveness. ${ }^{87}$ For instance, Dignam et $\mathrm{al}^{88,89}$ demonstrated equal efficacy of adjuvant tamoxifen and chemotherapy in African American and white breast cancer patients treated in cooperative group trials. Current patterns of treatment remain suboptimal, and nationally only one half of African American women with breast cancer who are eligible for systemic adjuvant chemotherapy are, in fact, receiving some form of systemic treatment. ${ }^{54}$

At present, we do not know the reasons for the divergence of the patterns of care and guidelines for African American women. It is possible that physicians are emphasizing treatment toxicity and quality of life, and not survival, or that patients are poorly informed about chemotherapy risks and benefits. Significant comorbidity or strong patient preferences may be very legitimate reasons for the omission of systemic adjuvant treatment, whereas lack of insurance, race, socioeconomic status, or incomplete understanding should not preclude this treatment. Unfortunately, there are pervasive differences in access to cancer treatment services, including chemotherapy and referral to a medical oncologist ${ }^{3}$ by race, income, education, or insurance and setting of care. ${ }^{90-98}$ Although National Cancer
Institute cooperative group trials have enrolled numbers of African Americans proportional to the population cancer burden, ${ }^{99}$ African Americans are still less likely to be offered trial participation than white patients. ${ }^{100}$

Patient beliefs may also affect patterns of care. Cancer is a disease with strong stigma. ${ }^{101-103}$ Cancer treatments are often perceived as "worse than the disease" and can "make you sicker instead of better." 104 Decision making and prognosis are often deferred to God: "If it's my time, God will decide" and "God directed me...to the treatments I had." 104 After the Tuskegee Study, such ideas are compounded by mistrust of the medical care system by African American patients. ${ }^{105,106}$

Our results suggest that substantial investments could be made in educational or other interventions to overcome barriers to care and improve referral for and uptake of systemic adjuvant therapy for breast cancer among African American women. Such investments results in costs per live years saved that are well within acceptable ranges. ${ }^{84}$ Examples of interventions that might be used to increase the proportion of African American women receiving recommended treatment include peer treatment workers (addressing trust and shared cultural perspectives), tailored decision aides (using cultural and patient-specific tailoring to overcome barriers), physician education (enhancing sensitivity and elicitation of patient preferences), and physician chart audit with feedback. We estimate that any of these approaches would cost less than our threshold of approximately $\$ 6,000$ per patient. However, given the complexity of treatment delivery and decisions and patient adherence, the optimal benefits projected in our model may not be fully realized, even with the best interventions. Nonetheless, given current patterns of care, any improvement in dissemination of recommended treatment should be cost effective.

The fact that screening rates are high in the United States and that rates are similar for African American and white patients ${ }^{13}$ reflects the success of decades of screening interventions. We evaluated the ability of the most effective (and least costly) interventions ${ }^{79,80}$ to further improve outcomes at the current point in time. Given the success of prior programs, additional efforts are quite expensive relative to the additional savings in lives, unless targeted to pockets of unscreened women or to women at twice the average risk of disease. Thus reaching hard to reach women who are unscreened or underscreened and educating women about risk factors remain important goals. It is also possible that screening results would differ with the availability of newer, more sensitive screening tests. Additionally, for women destined to develop ER-positive cancer, tamoxifen seems to be cost effective in high-risk white women. ${ }^{107}$ It will be important to examine the balance of risks and benefits for African American women, who have fewer ER-positive tumors and a higher prevalence of car- 
diovascular diseases that predispose to side effects than white women. ${ }^{108}$

Our model results are similar to other evaluations of screening in general populations. For instance, Elmore et $\mathrm{al}^{109}$ estimated that the cumulative risk for 40- to 49-yearold women having a false-positive mammogram is approximately $56 \%$ after 10 screens, and our model predicts a 54\% risk. Our estimate of the lifetime risk of breast cancer $(7.2 \%)$ is also similar to that calculated by Eddy ${ }^{21}$ in 1989 (approximately 6.5\%).

Our analysis has several important strengths, including use of current standards for cost-effectiveness analyses, ${ }^{26}$ evaluation of an important population subgroup, inclusion of the best quality and least biased data, a robust model, comparison of different cancer control strategies, and assessment of uncertainty.

Despite these strengths, there are several caveats that should be considered when interpreting our results, such as precision in estimating the natural history of breast cancer in African Americans, our method of evaluating mammography effectiveness and choice of screening technology, use of modeling, disutility of having a false-positive screen for cancer, ability to detect small effects, and generalizability. We have used the best data available to delineate the natural history of breast cancer in African American women. However, many aspects of the disease behavior are poorly understood, and there are insufficient data at this point in time to model other markers of disease aggressiveness. Our model is designed to incorporate such data as they become available.

Our results must be considered in the context of the current controversies about the effectiveness of mammography. ${ }^{110}$ We rely on observed stage distributions among screened and unscreened populations to calculate screening benefits. Our results are compatible with the view that screening is associated with small improvements in life expectancy. We did not evaluate the impact of new technologies that are currently under evaluation as alternative screening approaches, such as digital mammography or breast magnetic resonance imaging. When data are available on test characteristics of these strategies, we could reassess the cost effectiveness of the new technologies relative to mammography or to treatment enhancement.

Ideally, large-scale randomized studies would be conducted to evaluate optimal cancer control approaches in African American women. However, because breast cancer is a rare event, conducting trials of all possible approaches is not feasible (or ethical). Under these circumstances, models can be useful to combine the best data available and project events over a sufficiently long time horizon to observe incidence and mortality end points. ${ }^{111}$ To the extent that data are of poor quality, or assumptions are incorrect, model results can be inconclusive. However, there are reliable data on the natural history of breast neoplasia, and our results were robust over wide ranges of multiple parameters.

Our model does not capture the effects of distress associated with a falsely positive screen or the disutility of having cancer. We know of no data that measure breast cancer utilities among African American women. However, the transient nature of false-positives is not likely to alter conclusions of the analysis, and results were not sensitive to assumptions about utilities for cancer states.

There were very small screening benefits associated with enhanced use of mammography. It was difficult to detect larger screening intervention effects for several reasons. First, current rates of mammography use are quite high. ${ }^{13}$ At these rates, the modest effects of a prototypical intervention are insufficient to produce an appreciable effect on life expectancy. Second, this type of intervention has, in part, become part of standard care that we used as a comparator. Third, current treatment regimens for DCIS, local, and regional disease are highly effective. Large improvements in survival resulting from screening occur primarily in women who avoid presenting with distant disease. Such women represent only a minority of women in populations where screening is in widespread use. Finally, the relatively high cost-effectiveness ratio for enhanced screening compared with improving treatment is also related to the fact that screening the entire population is very costly. However, the benefits only accrue to the small number of women who develop cancer but are averaged over the whole population, yielding a small per woman benefit. In contrast, the costs of treatment interventions are applied to a much smaller number of women, all of whom will benefit directly.

Finally, our results are only generalizable to African American women. We did not examine results for black patients from other countries or for white women. Because certain populations of white patients, such as low-income or uninsured women in the United States, are also at risk for poor cancer outcomes, this will be an important area for future extensions of our model. The survival data we used may not be representative of the general population of African American women, because clinical trials generally enroll healthy volunteers. However, these trials did include a representative sample of African American women (10\% to $12 \%$ ), enhancing the external validity of our results.

The results of this cost-effectiveness analysis are intended to inform clinical and policy debates about cancer services for vulnerable populations. Overall, our results suggest that except in pockets of unscreened or high-risk women, investments in further improvements in screening use are unlikely to be an efficient use of limited health care resources. The most cost-effective interventions are likely to be those ensuring that African American women receive the most intensive treatment once cancer is diagnosed. 


\section{Acknowledgment and Appendix}

The acknowledgment and appendix are included in the full-text version of this article, available on-line at www.jco. org. They are not included in the PDF (via Adobe ${ }^{\circledR}$ Acrobat Reader $^{\circledR}$ ) version.

\section{REFERENCES}

1. Surveillance, Epidemiology and End Results: SEER cancer incidence, and stage mortality: Public-Use Database, 1973-1999. http:// seer.cancer.gov/csr/1973_1999/overview.pdf. Accessed on 3/18/02

2. Silverberg E, Boring CC, Squires TS: Cancer Statistics. CA Cancer J Clin 40:9-26, 1990

3. Chu KC, Tarone RE, Brawley OW: Breast cancer trends of black women compared with white women. Arch Fam Med 8:521-528, 1999

4. Breen $\mathrm{N}$, Wagener DK, Brown ML, et al: Progress in cancer screening over a decade: Results of cancer screening from the 1987, 1992, and 1998 national health interview surveys. J Natl Cancer Inst 93:1704-1713, 2001

5. Oakar MR: Legislative effect of the 102nd Congress: Cancer prevention, detection, treatment, and research. Cancer 69:1954-1956, 1992 (suppl)

6. Bickell NA, Kalet AL, Lin BC, et al: Mammography compliance in an inner city culturally diverse population. Clin Res 41:534A, 1993 (abstr)

7. Mandelblatt $\mathrm{J}$, Andrews $\mathrm{H}$, Kerner $\mathrm{J}$, et al: Determinants of late stage diagnosis of breast and cervical cancer: The impact of age, race, social class, and hospital type. Am J Public Health 81:646-649, 1991

8. Mandelblatt $J$, Andrews $H$, Kao R, et al: Impact of access and social context on breast cancer stage at diagnosis. J Health Care Poor Underserved 6:342-351, 1995

9. Jones BA, KasI SV, Curnen MG, et al: Can mammography screening explain the race difference in stage at diagnosis of breast cancer? Cancer 75:2103-2113, 1995

10. Hunter CP, Redmond $C K$, Chen VW, et al: Breast cancer: Factors associated with stage at diagnosis in black and white women-Black/ White Cancer Survival Study Group. J Natl Cancer Inst 85:1129-1137, 1993

11. Freeman HP, Wasfie TJ: Cancer of the breast in poor black women. Cancer 63:25622569, 1989

12. Wells BL, Horm JW: Stage at diagnosis in breast cancer: Race and socioeconomic factors. Am J Public Health 82:1383-1385, 1992

13. Blackman DK, Bennett EM, Miller DS: Trends in self-reported use of mammograms (1989-1997) and Papanicolaou tests (1991-1997): Behavioral Risk Factor Surveillance System. MMWR CDC Surveill Summ 48:1-22, 1999

14. McWhorter WP, Mayer WJ: Black/white differences in type of initial breast cancer treatment and implications for survival. Am J Public Health 77:1515-1517, 1987

15. Diehr P, Yergan J, Chu H, et al: Treatment modality and quality differences for black and white breast-cancer patients treated in community hospitals. Med Care 27:942-958, 1989

\section{Authors' Disclosures of Potential Conflicts of Interest}

The authors indicated no potential conflicts of interest.
16. Mandelblatt J, Kerner J, Hadley J, et al: Variations in breast cancer treatment in older medicare beneficiaries: Is it black or white? Cancer 95:1401-1414, 2002

17. de Koning $H$, van Ineveld $B$, van Oortmarssen G, et al: Breast cancer screening and cost-effectiveness; policy alternatives, quality of life considerations and the possible impact of uncertain factors. Int J Cancer 49:531-537, 1991

18. van der Maas PJ, de Koning HJ, van Ineveld BM, et al: The cost-effectiveness of breast cancer screening. Int J Cancer 43:10551060, 1989

19. Eddy D: Breast Cancer Screening for Medicare Beneficiaries: Effectiveness, Costs to Medicare and Medical Resources Required. Washington, DC, US Congress, Office of Technology Assessment, Health Program, Washington, DC, 1987

20. Lindfors KK, Rosenquist CJ: The costeffectiveness of mammographic screening strategies. JAMA 274:881-884, 1995

21. Eddy DM: Screening for breast cancer. Ann Intern Med 111:389-399, 1989

22. Desch $C E$, Hillner $B E$, Smith $T J$, et al: Should the elderly receive chemotherapy for node-negative breast cancer? A costeffectiveness analysis examining total and active life-expectancy outcomes. J Clin Oncol 11:777782, 1993

23. Brown ML: Economic considerations in breast cancer screening of older women. J Gerontol 47:51-58, 1992

24. Kerlikowske K, Salzmann P, Phillips KA, et al: Continuing screening mammography in women aged 70 to 79 years: Impact on life expectancy and cost-effectiveness. JAMA 282: 2156-2163, 1999

25. Mandelblatt J, Wheat ME, Monane M, et al: Breast cancer screening for elderly women with and without comorbid conditions: A decision analysis model. Ann Intern Med 116:722 730, 1992

26. Gold MR, Siegel JE, Russel LB, et al: Cost-Effectiveness in Health and Medicine. New York, NY, Oxford University Press, 1996

27. Rubenstein RY: Simulation and the Monte Carlo Method. New York, NY, John Wiley \& Sons, 1981

28. Beck JR, Pauker SG: The Markov process in medical prognosis. Med Decis Making 3:419458, 1983

29. Eley JW, Hill HA, Chen VW, et al: Racial differences in survival from breast cancer: Results of the National Cancer Institute Black/ White Cancer Survival Study. JAMA 272:947954, 1994

30. Elledge RM, Clark GM, Chamness GC, et al: Tumor biologic factors and breast cancer prognosis among white, Hispanic, and black women in the United States. J Natl Cancer Inst 86:705-712, 1994
31. Gapstur SM, Dupuis J, Gann P, et al: Hormone receptor status of breast tumors in black, Hispanic, and non-Hispanic white women An analysis of 13,239 cases. Cancer 77:14651471, 1996

32. Mohla S, Sampson CC, Khan T, et al: Estrogen and progesterone receptors in breast cancer in Black Americans: Correlation of receptor data with tumor differentiation. Cancer 50 552-559, 1982

33. Crowe JP Jr, Gordon NH, Hubay CA, et al: The interaction of estrogen receptor status and race in predicting prognosis for stage I breast cancer patients. Surgery 100:599-605, 1986

34. Simon MS, Severson RK: Racial differences in survival of female breast cancer in the Detroit metropolitan area. Cancer 77:308-314 1996

35. Russo J, Hu YF, Yang $X$, et al: Developmental, cellular, and molecular basis of human breast cancer. J Natl Cancer Inst Monogr 27:1737, 2000

36. Kaptain S, Tan LK, Chen B: Her-2/neu and breast cancer. Diagn Mol Pathol 10:139-152, 2001

37. Melnikow J, Kohatsu ND, Chan B: Put prevention into practice: A controlled evaluation. Am J Pub Health 90:1622-1625, 2000

38. Beck JR, Pauker SG, Gottlieb JE, et al: A convenient approximation of life expectancy (THE "DEALE"): II. Use in medical decisionmaking. Am J Med 73:889-897, 1982

39. Ballard-Barbash R, Taplin SH, Yankaskas $B C$, et al: Breast Cancer Surveillance Consortium: A national mammography screening and outcomes database. AJR Am J Roentgenol 169 : 1001-1008, 1997

40. Shapiro $S$, Venet $W$, Strax $P$, et al: Periodic Screening for Breast Cancer: The Health Insurance Plan Project and Its Sequelae, 196386. Baltimore, MD, Johns Hopkins University Press, 1988

41. Andersson I, Aspegren $K$, Janzon $L$, et al: Mammographic screening and mortality from breast cancer: The Malmo mammographic screening trial. BMJ 297:943-948, 1988

42. Roberts MM, Alexander FE, Anderson TJ, et al: Edinburgh trial of screening for breast cancer: Mortality at seven years. Lancet 335 241-246, 1990

43. Brekelmans CTM, Westers $P$, Faber JAJ, et al: Age specific sensitivity and sojourn time in a breast cancer screening programme (DOM) in the Netherlands: A comparison of different methods. J Epidemiol Community Health 50:68 71, 1996

44. Paci E, Duffy SW: Modeling the analysis of breast cancer screening programmes: Sensitivity, lead time and predictive values in the Florence district programme (1975-1986). Int J Epidemiol 20:852-858, 1991 
45. Kerlikowske K, Grady D, Barclay J, et al: Likelihood ratios for modern screening mammography: Risk of breast cancer based on age and mammographic interpretation. JAMA 276: 39-43, 1996

46. Wolosin RJ: Effect of appointment scheduling and reminder postcards on adherence to mammography recommendations. J Fam Pract 30:542-547, 1990

47. Taplin SH, Anderman C, Grothaus L, et al: Using physician correspondence and postcard reminders to promote mammography use. Am J Public Health 84:571-574, 1994

48. Somkin CP, Hiatt RA, Hurley LB, et al: The effect of patient and provider reminders on mammography and papanicolaou smear screening in large health maintenance organization. Arch Intern Med 157:1658-1664, 1997

49. Calle EE, Miracle-McMahill HL, Moss RE, et al: Personal contact from friends to increase mammography usage. Am J Prev Med 10:361366, 1994

50. Sung JF, Blumenthal DS, Coates RJ, et al: Effect of cancer screening intervention conducted by lay health workers among inner-city women. Am J Prev Med 13:51-57, 1997

51. Navarro AM, Senn KL, McNicholas LJ, et al: Por La Vida model intervention enhances use of cancer screening test among Latinas. Am J Prev Med 15:32-41, 1998

52. Gotay CC, Banner R, Matsunaga DS, et al: Impact of a culturally appropriate intervention on breast and cervical screening among native Hawaiian women. Prev Med 31:529-537, 2000

53. Anderson MR, Yasui $Y$, Meischke $H$, et al: The effectiveness of mammography promotion by volunteers in rural communities. Am J Prev Med 18:199-207, 2000

54. Harlan LC, Abrams J, Warren JL, et al: Adjuvant therapy for breast cancer: Practice patterns of community physicians. J Clin Oncol 20:1809-1817, 2002

55. Update of the NCCN guidelines for treatment of breast cancer. Oncology 11:199-220, 1997

56. Goldhirsch A, Glock J, Gelber R, et al: Meeting Highlights: International Consensus Panel on the Treatment of Primary Breast Cancer. J Clin Oncol 19:3817-3827, 2001

57. Fisher B, Anderson S, Tan-Chiu E, et al: Tamoxifen and chemotherapy for axillary nodenegative, estrogen receptor-negative breast cancer: Findings from National Surgical Adjuvant Breast and Bowel Project B-23. J Clin Oncol 19:931-942, 2001

58. Tamoxifen in treatment of intraductal breast cancer: National Surgical Adjuvant Breast and Bowel Project B-24 randomised controlled trial. Lancet 353:1993-2000, 1999

59. Fisher B, Anderson S, DeCillis A, et al: Further evaluation of intensified and increased total dose of cyclophosphamide for the treatment of primary breast cancer: Findings from National Surgical Adjuvant Breast and Bowel Project B-25. J Clin Oncol 17:3374-3388, 1999

60. Smith RE, Brown AM, Mamounas EP, et al: Randomized trial of 3-hour versus 24 hour infusion of high-dose paclitaxel in patients with metastatic or locally advanced breast cancer: National Surgical Adjuvant Breast and Bowel
Project Protocol B-26. J Clin Oncol 17:34033411, 1999

61. Fisher B, Dignam J, Wolmark N, et al: Tamoxifen and chemotherapy for lymph nodenegative, estrogen receptor-positive breast cancer. J Natl Cancer Inst 89:1673-1682, 1997

62. Fisher B, Anderson S, Wickerham DL, et al: Increased intensification and total dose of cyclophosphamide in a doxorubicin-cyclophosphamide in a doxorubicin-cyclophosphamide regimen for the treatment of primary breast cancer: Findings from National Surgical Adjuvant Breast and Bowel Project B-22. J Clin Oncol 15:1858-1869, 1997

63. Fisher B, Dignam J, Mamounas EP, et al: Sequential methotrexate and fluorouracil for the treatment of node-negative breast cancer patients with estrogen receptor-negative tumors: Eight-year results from National Surgical Adjuvant Breast and Bowel Project (NSABP) B-13 and first report of findings from NSABP B-19 comparing methotrexate and fluorouracil with conventional cyclophosphamide, methotrexate, and fluorouracil. J Clin Oncol 14:1982-1992, 1996

64. Fisher B, Redmond CF, Costantino J, et al: Lumpectomy compared with lumpectomy and radiation therapy for the treatment of intraductal breast cancer. N Engl J Med 328:15811586, 1993

65. Fisher B, Brown AM, Dimitrov NV, et al: Two months of doxorubicin-cyclophosphamide with and without interval reinduction therapy compared with 6 months of cyclophosphamide, methotrexate, and fluorouracil in positive-node breast cancer patients with tamoxifennonresponsive tumors: Results from the $\mathrm{Na}$ tional Surgical Adjuvant Breast and Bowel Project B-15. J Clin Oncol 8:1483-1496, 1990

66. Fisher B, Redmond C, Legault-Poisson S, et al: Postoperative chemotherapy and tamoxifen compared with tamoxifen alone in the treatment of positive-node breast cancer patients aged 50 years and older with tumors responsive to tamoxifen: Results from the National Surgical Adjuvant Breast and Bowel Project B-16. J Clin Oncol 8:1005-1018, 1990

67. Fisher B, Costantino J, Redmond C, et al: $A$ randomized clinical trial evaluating tamoxifen in the treatment of patients with node-negative breast cancer who have estrogen-receptorpositive tumors. N Engl J Med 320:479-484, 1989

68. Fisher B, Redmond C, Dimitrov NV, et al: $A$ randomized clinical trial evaluating sequential methotrexate and fluorouracil in the treatment of patients with node-negative breast cancer who have estrogen-receptor-negative tumors. N Engl J Med 320:473-478, 1989

69. Fisher B, Redmond C, Fisher ER, et al: Ten-year results of a randomized clinical trial comparing radical mastectomy and total mastectomy with or without radiation. $\mathrm{N}$ Engl J Med 312:674-681, 1985

70. Schweitzer ME, French MT, UIImann SG, et al: Cost effectiveness of detecting breast cancer in lower socioeconomic status African American and Hispanic women through mobile mammography services. Med Care Res Rev 55:99-115, 1998

71. Health Care Financing Administration: Mammography services. http://www.hcfa.gov/ news/ncireq.htm
72. Brown ML, Houn F: Quality assurance audits of community screening mammography practices: Availability of active follow-up for data collection and outcome assessment. AJR Am J Roentgenol 163:825-829, 1994

73. Warren JL, Brown ML, Fay MP, et al: Costs of treatment for elderly women with earlystage breast cancer in fee-for-service settings J Clin Oncol 20:307-316, 2002

74. Agency for Healthcare Research and Quality: Healthcare Cost and Utilization Project III, 1997. http://www.ahrq.gov

75. National Center for Health Statistics, Centers for Disease Control and Prevention: National Health Interview Survey (NHIS): Cancer Prevention and Control Supplement, 1992 http://www.cdc.gov/nchs/nhis.htm

76. Secker-Walker R, Vacek P, Hooper G, et al: Screening for breast cancer: Time, travel, and out-of-pocket expenses. J Natl Cancer Inst 91 702-708, 1999

77. The Red Book: Medical Economics. Montclair, NJ, 2001

78. United States Bureau of the Census: Current Population Survey, July 2002. http:// www.bls.census/gov/cps/cpsmain.htm

79. Mandelblatt J, Kanetsky PA: Effectiveness of interventions to enhance physician screening for breast cancer. J Fam Pract 40:162170, 1995

80. Yabroff KR, Mandelblatt JS: Interventions targeted to patients to increase mammography use. Cancer Epidemiol Biomarkers Prev 8:749 757, 1999

81. National Center for Health Statistics http://www.cdc.gov/nchswww/data/hp2k99.pdf

82. Bureau of Labor Statistics, 2000: Consumer price index. http://www.bls.gov/datahome.htm

83. Brown ML, Riley GF, Schussler N, et al Estimating health care costs related to cancer treatment from SEER-Medicare data. Med Care 40:104-117, 2002

84. Luce BR, Manning WG, Siegel JE, et al: Estimating costs in cost-effectiveness analysis, in Gold MR, Siegel JE, Russell LB, et al (eds): Cost-Effectiveness in Health and Medicine. New York, NY, Oxford University Press, 1996, pp 176-213

85. Early Breast Cancer Trialists' Collaborative Group: Polychemotherapy for early breast cancer: An overview of the randomised trials. Lancet 352:930-942, 1998

86. Early Breast Cancer Trialists' Collaborative Group: Tamoxifen for early breast cancer: An overview of the randomised trials. Lancet 351 1451-1467, 1998

87. Roach M, Cirrincione C, Budman D, et al Race and survival from breast cancer: Based on Cancer and Leukemia Group B Trial 8541. Cancer J Sci Am 3:107-112, 1997

88. Dignam JJ, Redmond CK, Fisher B, et al: Prognosis among African American women and white women with lymph node negative breast carcinoma: Findings from two randomized clinical trials of the National Surgical Adjuvant Breast and Bowel Project (NSABP). Cancer 80:80-90, 1997

89. Dignam J: Efficacy of systemic adjuvant therapy for breast cancer in African American 
and Caucasian Women. J Natl Cancer Inst Monogr 36-43, 2001

90. Potosky AL, Merrill RM, Riley GF, et al: Breast cancer survival and treatment in health maintenance organization and fee-for-service settings. J Natl Cancer Inst 89:1683-1691, 1997

91. Potosky AL, Harlan LC, Kaplan RS, et al: Age, sex and racial differences in the use of standard adjuvant therapy for colorectal cancer. J Clin Oncol 20:1192-1202, 2002

92. Shavers VL, Brown ML: Racial and ethnic disparities in the receipt of cancer treatment. J Natl Cancer Inst 94:334-357, 2002

93. Bach PB, Cramer LD, Warren JL, et al: Racial differences in the treatment of early- stage lung cancer. N Engl J Med 341:11981205, 1999

94. Cooper GS, Yuan Z, Landefeld CS, et al: Surgery for colorectal cancer: Race-related differences in rates and survival among Medicare beneficiaries. Am J Public Health 86:582-586, 1996

95. Ball JK, Elixhauser A: Treatment differences between blacks and whites with colorectal cancer. Med Care 34:970-984, 1996

96. Harlan L, Brawley O, Pommerenke F et al: Geographic, age, and racial variation in the treatment of local/regional carcinoma of the prostate. J Clin Oncol 13:93-100, 1995
97. Klabunde $C N$, Potosky $A L$, Harlan LC, et al: Trends and black/white differences in treatment for nonmetastatic prostate cancer. Med Care 36:1337-1348, 1998

98. Roetzheim RG, Gonzalez EC, Ferrante $J M$, et al: Effects of health insurance and race on breast carcinoma treatments and outcomes. Cancer 89:2202-2213, 2000

99. Tejeda HA, Green SB, Trimble EL, et al Representation of African Americans, Hispanics, and whites in National Cancer Institute cancer treatment trials. J Natl Cancer Inst 88:812-816, 1996

100. Brown ML, Hankey BF, Ballard-Barbash R: Measuring the quality of breast cancer care. Ann Intern Med 133:920, 2000

References 101-111 are included in the full-text version of this article, available on-line at www.jco.org. They are not included in the PDF (via Adobe ${ }^{\circledR}$ Acrobat Reader $^{\circledR}$ ) version. 